\title{
AIDS-Related Kaposi Sarcoma T (Tumor)
}

\section{Status}

National Cancer Institute

\section{Source}

National Cancer Institute. AIDS-Related Kaposi Sarcoma T (T umor) Status. NCI

Thesaurus. Code C134970.

A term that refers to the tumor status of AIDS-related Kaposi sarcoma according to the AIDS Clinical T rials Group system. (American Cancer Society) 